\title{
The ROS/JNKJATF2 pathway mediates selenite- induced leukemia NB4 cell cycle arrest and apoptosis in vitro and in vivo
}

\author{
JJ An ${ }^{1}, \mathrm{KJ} \mathrm{Shi}{ }^{1}$, W Wei ${ }^{1}, \mathrm{FY} \mathrm{Hua}^{1}, \mathrm{YL} \mathrm{Ci}{ }^{1}, \mathrm{Q} \mathrm{Jiang}^{1}, \mathrm{~F} \mathrm{Li}{ }^{1}, \mathrm{P} \mathrm{Wu}{ }^{1}, \mathrm{KY} \mathrm{Hui}^{1}, \mathrm{Y}$ Yang ${ }^{1}$ and $\mathrm{CM} \mathrm{Xu^{* } , 1}$
}

It has previously been shown that selenite can act as an antitumor agent and inhibit cancer cell growth, although the mechanism responsible for this effect is not well understood. In this study, we have shown that selenite can induce cell cycle arrest and apoptosis in NB4 cells. Selenite treatment of these cells also inhibited the JNK/ATF2 axis. Further experiments demonstrated that selenite-induced production of reactive oxygen species (ROS) worked as an upstream of the JNK/ATF2 axis, cell cycle arrest and apoptosis. Inactivation of ATF2 resulted in decreased affinity of this transcription factor for the promoters of cyclin A, cyclin D3 and CDK4, which led to the arrest of the NB4 cells in the G0/G1 phase. Finally, in vivo experiments confirmed the antitumor activity of selenite and the mechanisms that were described in vitro. Taken together, our results indicate that selenite-induced ROS arrest NB4 cells at G0/G1 phase through inhibiting the JNK/ATF2 axis in vitro and in vivo.

Cell Death and Disease (2013) 4, e973; doi:10.1038/cddis.2013.475; published online 19 December 2013

Subject Category: Cancer

Acute promyelocytic leukemia (APL) is a well-described form of acute leukemia that is cytogenetically characterized by a $t(15 ; 17)$ (q22; q11-12) translocation and the expression of the PML-RAR $\alpha$ fusion protein. ${ }^{1}$ The continuous cell line NB4 is derived from the bone marrow of a patient with relapsing APL. ${ }^{2}$ Although all-trans retinoic acid (ATRA) and arsenic trioxide have been successful in treating APL, undesirable side effects and drug resistance have greatly limited the application of these drugs. ${ }^{3-5}$

Selenium is an essential trace element. Super-nutritional selenium intake has been reported to induce apoptosis through multiple signaling pathways. ${ }^{6-9}$ Selenite is an inorganic form of selenium that induces growth inhibition in multiple tumor cell lines. Several reports have demonstrated that selenite is also toxic to multiple types of drug-resistant tumor cells. ${ }^{10}$ Moreover, we have shown that selenite can cure HL60 cell-bearing nude mice in vivo. ${ }^{6}$ If the effects of selenite on tumor cells can be clarified, this information can be used for potential therapeutic applications of this element.

Reactive oxygen species (ROS) are active forms of oxygen that are derived from normal oxygen metabolic processes. Our previous study described selenite-induced apoptosis of NB4 cells via ROS. ${ }^{11-13}$ However, the exact mechanisms of this apoptosis are still not well understood. In our cDNA microarray analysis, we observed that some cell cycle-related proteins were significantly altered in selenite-treated NB4 cells, which indicated that selenite might have a role in cell cycle regulation. ${ }^{14}$ Although a relationship between ROS and cell cycle arrest has previously been described, ${ }^{15}$ the exact mechanisms by which ROS regulate cell cycle progression have not been well explored.

ATF2 is a CREB (cAMP response element binding) family member. Normally, ATF2 regulates and heterodimerizes with other transcription factors, including c-Jun and C-Fos. ${ }^{16}$ The activation of ATF2 usually requires phosphorylation by other kinases such as JNK, ERK or p38 MAPK, some of which have been reported to be regulated by ROS. ${ }^{17-19}$ ATF2 targets include several pro-survival molecules such as cell cycle-related proteins. ${ }^{16}$ Therefore, we are interested in examining the role of ATF2 as a bridge between ROS and cell cycle arrest.

In this study, we investigated the mechanisms underlying the anticancer effects of sodium selenite on NB4 cells. Our results indicated that sodium selenite induced cell cycle arrest and apoptosis of NB4 cells via a ROS/JNK/ATF2 pathway.

\section{Results}

Selenite inhibits cell cycle progression and induces apoptosis in NB4 cells. Previous studies have demonstrated that selenite can induce tumor cell apoptosis and has anticancer effects in vivo. Consistent with these results, both Annexin V/PI double-staining experiment and TUNEL assay showed that $20 \mu \mathrm{M}$ selenite induced apoptosis and necrosis

\footnotetext{
${ }^{1}$ State Key Laboratory of Medical Molecular Biology, Department of Biochemistry and Molecular Biology, Institute of Basic Medical Sciences and School of Basic Medicine, Peking Union Medical College and Chinese Academy of Medical Sciences, Beijing, China

${ }^{*}$ Corresponding author: CM Xu, Department of Biochemistry and Molecular Biology, National Laboratory of Medical Molecular Biology, Institute of Basic Medical Sciences, CAMS \& PUMC, Dong Dan San Tiao wu hao, Beijing 100005, China; Tel: +86 10 69156445; Fax: +86 10 69156445; E-mail: cmxu@ibms.pumc.edu.cn Keywords: selenite; ROS; JNK; ATF2; cyclin; apoptosis

Abbreviations: APL, acute promyelocytic leukaemia; PMSF, phenylmethanesulfonyl fluoride; PD0332991, a cyclin-dependent kinase (CDK) inhibitor; JNK, c-Jun NH2terminal kinase; SP600125, c-Jun N-terminal kinase inhibitor; MnTMPyP, Mn (III) tetrakis (I-methyl-4-pridyl) porphyrin pentachloride; PI, propidium iodide; DCFH-DA, $2^{\prime}, 7^{\prime}$-dichlorodihydrofluorescein diacetate; H\&E staining, hematoxylin-eosin staining; ATF2, activating transcription factor; DAPI, 4',6-diamidino-2-phenylindole; TUNEL, TdT-mediated dUTP nick-end labeling

Received 23.9.13; revised 31.10.13; accepted 31.10.13; Edited by A Finazzi-Agró
} 
of NB4 cells in a time-dependent manner (Figures 1a and b). BrdU staining was also applied to examine the effects of selenite on DNA synthesis in NB4 cells. Selenite treatment for $6 \mathrm{~h}$ slightly increased the proportion of FITC-positive cells, indicating that the DNA synthesis activity of NB4 cells was slightly promoted at $6 \mathrm{~h}$. As the treatment time was increased, DNA synthesis in NB4 cells became increasingly repressed as demonstrated by the significant decrease in the proportion of FITC-positive cells (Figure 1c).

As DNA replication is the hallmark of $S$ phase, we hypothesized that cell cycle progression was being impacted. Flow cytometric analysis indicated that selenite-treated NB4 cells were arrested at the G0/G1 phase in a dose-dependent manner (Figure 1d). To fully demonstrate the effects of selenite on NB4 cells, whole-cell lysates were extracted and western blotting was performed (Figure 1e). As expected, the expression levels of CDK4, phospho-Rb, cyclin D3 and cyclin A, which are markers that are representative of $\mathrm{G0} / \mathrm{G} 1$ activity, were decreased. Additionally, both caspase-3 and
PARP were cleaved in a time-dependent manner following selenite treatment, indicating that selenite induced apoptosis. We also found that the JNK-ATF2 axis was inhibited in addition to cell cycle arrest in NB4 cells. These results suggest that selenite-induced apoptosis may be related to the alteration of cell cycle progression and the inhibition of the JNK/ATF2 axis.

Selenite-induced ROS are involved in regulating the JNK/ATF2 axis, cell cycle progression and apoptosis. The previous experiments indicated that selenite could induce cell cycle arrest in NB4 cells. Before cell cycle arrest, the intracellular ROS hydrogen peroxide can be detected using a DCF (dichlorodihydrofluorescein) assay. We observed that treatment with $20 \mu \mathrm{M}$ selenite rapidly promoted the generation of hydrogen peroxide, while combined treatment with MnTMPyP, a ROS scavenger, and selenite could significantly reverse this increase in hydrogen peroxide formation (Figure 2a).

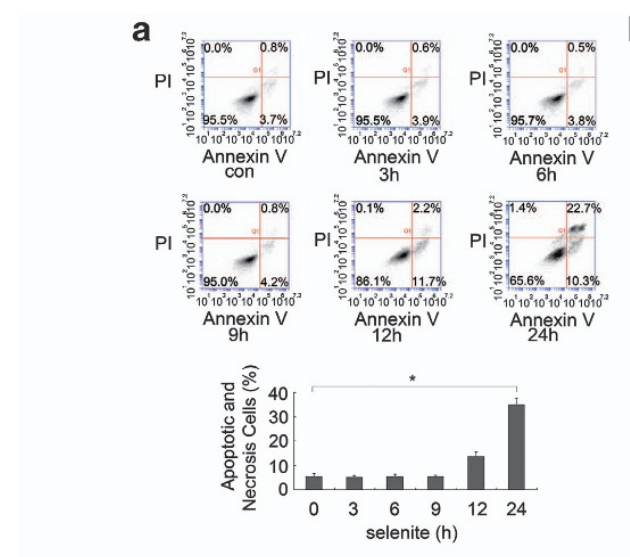

b
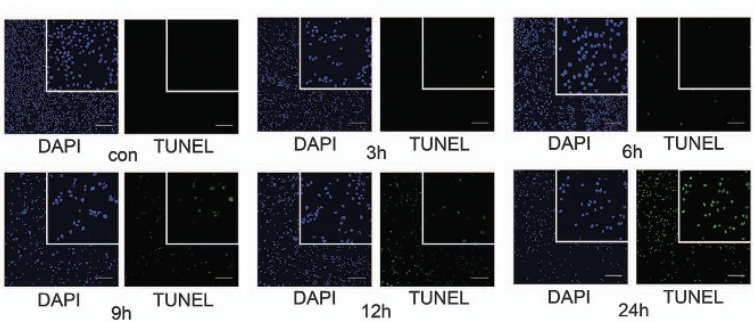

C
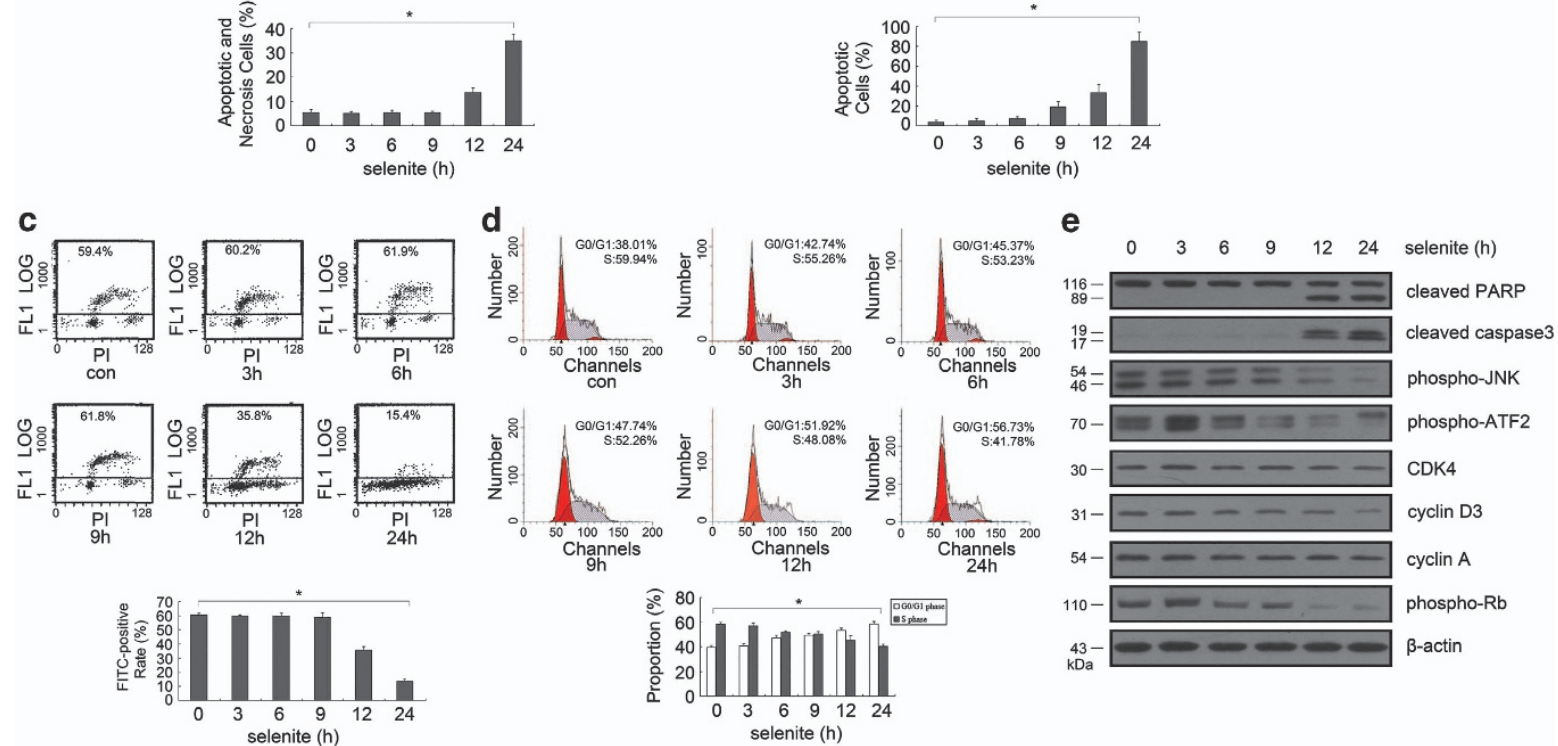

Figure 1 Selenite induced cell cycle arrest and apoptosis in NB4 cells. (a) Selenite caused NB4 cell apoptosis in a time-dependent manner. After exposure to $20 \mu \mathrm{M}$ selenite for various amounts of time, cells were collected and labeled with Annexin V/PI for flow cytometric analysis. The bar graphs represented the mean values of the apoptotic and necrotic cells, and the experiments were repeated at least three times. (b) TUNEL assay also confirmed selenite apoptosis promotion effects. After cells were treated with $20 \mu \mathrm{M}$ selenite for various length of time, TUNEL assay was performed to calculate the number of apoptotic and necrotic cells. Bar: $100 \mu \mathrm{m}$. (c) Selenite inhibited DNA synthesis in NB4 cells. For flow cytometric analysis, cells were cultured in medium containing $20 \mu \mathrm{M}$ selenite for the indicated times and then pulse-labeled with $20 \mu \mathrm{M}$ BrdU under normal culture conditions in the dark for $30 \mathrm{~min}$. Cells were then harvested and incubated with $100 \mu \mathrm{l} \mathrm{FITC-conjugated} \mathrm{anti-BrdU} \mathrm{for} 1 \mathrm{~h}$ before being stained with PI. Cells actively synthesizing DNA had FITC values above the baseline. Numbers on each image show the percentage of cells above the baseline in each group. (d) Selenite arrested NB4 cells in the G0/G1 phase. After treatment with different doses of selenite, cells were evaluated by flow cytometric analysis. The bar graphs represented the mean values of the apoptotic and necrotic cells, and the experiments were repeated at least three times. ${ }^{*} P<0.05$. (e) Selenite attenuated the JNK/ATF2 axis and the expression of cell cycle-related proteins. After cells were exposed to $20 \mu \mathrm{M}$ selenite for the indicated times, the levels of cell cycle-related proteins, markers of apoptosis and the JNK/ATF2 axis were detected with western blot 
To further explore the function of ROS in apoptosis and cell cycle progression, Annexin V/PI double-staining experiment and TUNEL assay were carried out, both of which showed that inhibiting ROS production could reverse the effects of selenite on apoptosis induction (Figures $2 \mathrm{~b}$ and $\mathrm{c}$ ). Moreover, flow cytometric analysis also indicated that cell cycle arrest was canceled along with ROS scavenging (Figure 2d). Finally, we pre-treated NB4 cells with MnTMPyP for $1 \mathrm{~h}$ before selenite exposure. Western blotting indicated that selenite-induced decreases in cyclin D1, cyclin D3, CDK4, cyclin A and phospho- $\mathrm{Rb}$ were reversed following MnTMPyP pretreatment, while the selenite-induced activation of caspase- 3 and PARP was abolished by this pretreatment. Meanwhile, the combined use of MnTMPyP and selenite also rescued the inhibition of the JNK/ATF2 axis. Notably, cells that were treated with $\mathrm{H}_{2} \mathrm{O}_{2}$ were used as a positive control and proved a
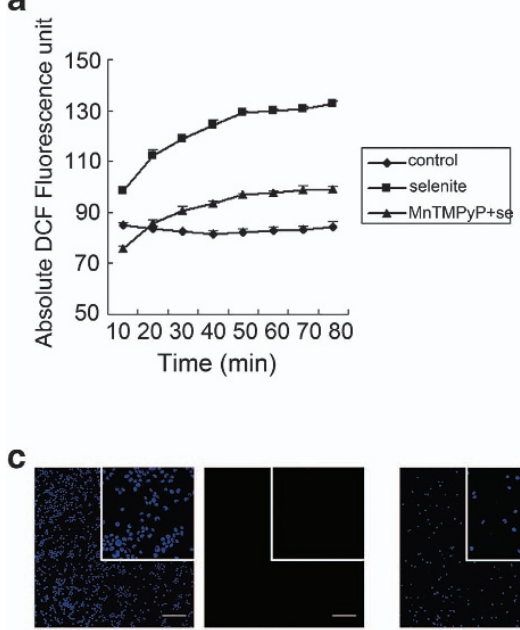

DAPI

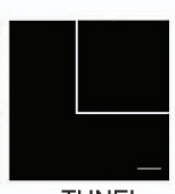

con

TUNEL

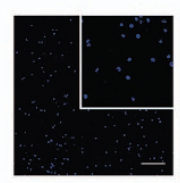

DAPI
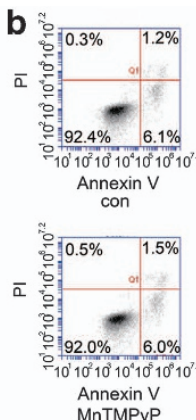

MnTMPyP

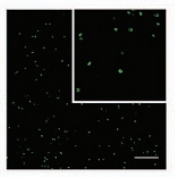

TUNEL

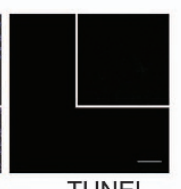

MnTMPyP+se
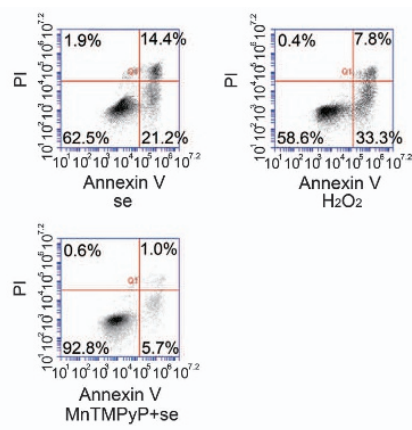

$\mathrm{H}_{2} \mathrm{O}_{2}$

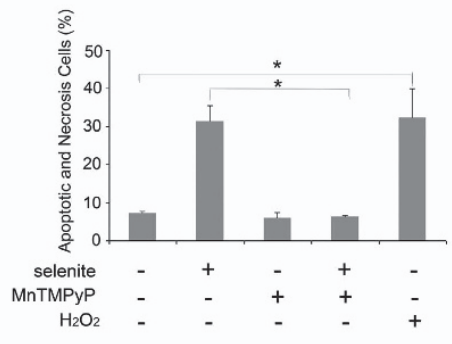

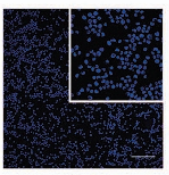

DAPI

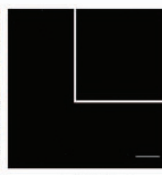

MnTMPyP

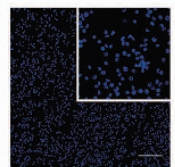

DAPI

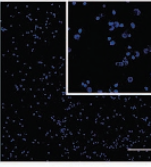

DAPI

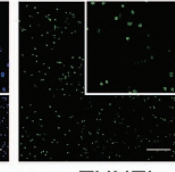

$\mathrm{H}_{2} \mathrm{O}_{2}$

TUNEL

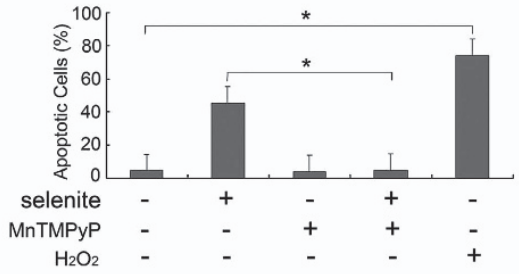

d
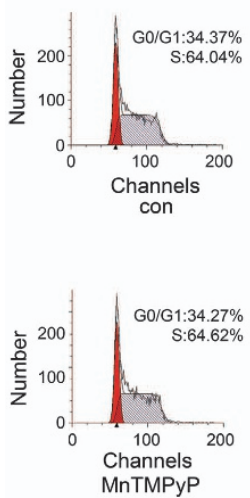

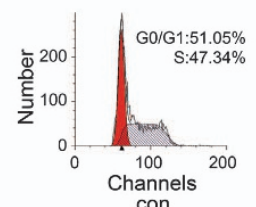

con

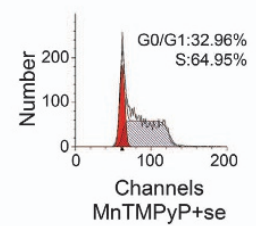

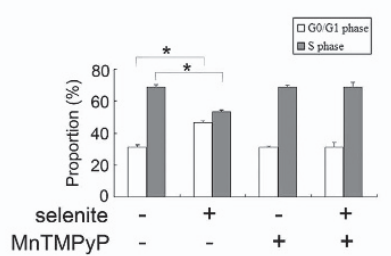

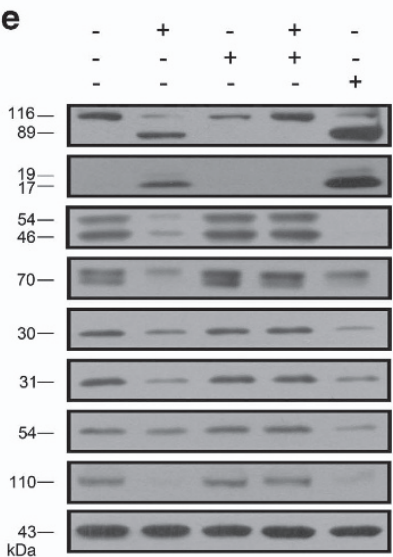

selenite MnTMPyP $\mathrm{H}_{2} \mathrm{O}_{2}$ cleaved PARP cleaved caspase 3 phospho-JNK phospho-ATF2 CDK4 cyclin D3 cyclin A phospho-Rb $\beta$-actin

Figure 2 ROS regulated selenite-induced cell cycle arrest, apoptosis and JNK/ATF2 axis inhibition. (a) Selenite induced ROS generation. After labeling cells with DCF in the dark, cells were treated with $20 \mu \mathrm{M}$ selenite. Data were represented as the mean \pm S.D. (b and c) Selenite-induced ROS production caused apoptosis in NB4 cells. Cells were pretreated with $10 \mu \mathrm{M}$ MnTMPyP for $1 \mathrm{~h}$ and then treated with $20 \mu \mathrm{M}$ selenite for another $24 \mathrm{~h}$. Cells treated with $50 \mu \mathrm{M} \mathrm{H}_{2} \mathrm{O}_{2}$ were used as a positive control. Annexin V/PI staining was performed and analyzed by flow cytometry to detect apoptosis and necrosis. Data were represented as the mean \pm S.D. TUNEL assay was performed to calculate the number of apoptosis cells. Bar: $100 \mu \mathrm{m}$. ${ }^{*} P<0.05$. (d) Selenite-induced ROS production led NB4 cells to be arrested at G0/G1 phase. Cells were pretreated with $10 \mu \mathrm{M}$ MnTMPyP for $1 \mathrm{~h}$, and then cells were treated with $20 \mu \mathrm{M}$ selenite for another $24 \mathrm{~h}$. Cells treated with $50 \mu \mathrm{M} \mathrm{H}_{2} \mathrm{O}_{2}$ were used as a positive control. Flow cytometry analysis was performed to detect cell cycle progression. Data were represented as the mean \pm S.D. ${ }^{*} P<0.05$. (e) ROS attenuated the JNK/ATF2 axis and the expression of cell cycle-related proteins. Cells that were treated with $50 \mu \mathrm{M} \mathrm{H}_{2} \mathrm{O}_{2}$ were used as a positive control. MnTMPyP and selenite were used in combination, and then markers of apoptosis and the JNK/ATF2 axis were detected via western blot 
that ROS could also result in the cell cycle arrest, apoptosis induction and JNK/ATF2 axis inhibition (Figure 2e).

The JNKJATF2 axis regulates selenite-induced cell cycle arrest and apoptosis. The experiments described above showed that selenite-induced ROS caused inhibition of the JNK-ATF2 axis. We attempted to further determine whether the JNK-ATF2 axis participated in the regulation of cell cycle progression and apoptosis. First, the interaction between JNK and ATF2 was confirmed. After treatment with $20 \mu \mathrm{M}$ selenite for $24 \mathrm{~h}$, cells were harvested and lysed on ice. Immunoprecipitation was performed to determine whether JNK interacted with ATF2. An interaction between JNK and ATF2 was observed, and this binding was attenuated after selenite exposure (Figure 3a). Meanwhile, JNK and ATF2 were indirectly labeled. As you can see, ATF2 interacted with JNK mainly in the nucleus, while they were separated after selenite exposure (Figure $3 b$ ).

Following pretreatment with siRNA targeting JNK or SP600125 (the specific inhibitor of JNK), cells were exposed to selenite for another $24 \mathrm{~h}$. Western blot results indicated that inhibiting the activation or expression of JNK further reduced the selenite-induced levels of phospho-ATF2, cyclin A, CDK4 and cyclin D3, whereas increased levels of cleaved caspase-3 and PARP were observed (Figures $3 \mathrm{c}$ and f). To fully demonstrate the function of JNK in this system, we overexpressed constitutively active JNK plasmid and observed that the selenite-induced downregulation of phospho-ATF2, cyclin A, CDK4 and cyclin D3 was reversed and that the selenite-induced activation of caspase-3 and PARP was inhibited (Figure 3i). Finally, Annexin V/PI double staining and TUNEL assay also indicated that inhibiting JNK resulted in enhanced apoptosis, whereas overexpression of JNK led to a fewer apoptotic and necrotic cells than selenite alone (Figures 3d, e, g, h, j and k).

ATF2 regulates cell cycle-related protein expression. JNK has an important role in modulating cell cycle progression. ATF2, a transcription factor, has also been shown to be activated by JNK. Therefore, we speculated that ATF2 might be involved in regulating cell cycle-related protein expression. Using a ChIP assay, we found that ATF2 bound to the promoters of cyclin D3, cyclin A and CDK4 and that this interaction was attenuated by selenite (Figure 4a). Furthermore, after inhibiting ATF2 expression using siRNA interference and selenite worked for another $24 \mathrm{~h}$, western blot analysis indicated that ATF2 inhibition resulted in a further decrease in phospho-Rb, cyclin D3, cyclin A and CDK4, whereas increased cleavages of caspase- 3 and PARP were observed (Figure 4b).

When ATF2 overexpression plasmids were transfected into NB4 cells, this overexpression inhibited the downregulation of phospho-Rb, cyclin D3, cyclin A and CDK4 and reduced the cleavages of caspase-3 and PARP (Figure 4e). Annexin V/PI double-staining analysis and TUNEL assay were performed to investigate the anti-apoptotic role of ATF2. These experiments indicated that inhibiting ATF2 resulted in enhanced apoptosis, whereas overexpression of ATF2 led to a fewer apoptotic and necrotic cells (Figures 4c, d, f and g). Finally, we performed a combined treatment of CDK4 inhibitor and selenite. As expected, increased cleavages of caspase-3 and PARP were observed (Figure 4f), which indicated that apoptosis was enhanced. This conclusion was also supported by flow cytometric analysis and TUNEL assay (Figures $4 \mathrm{i}$ and $\mathrm{j}$ ).

Selenite has therapeutic effects in vivo. After exploring the important role of the JNK/ATF2 axis following selenite treatment in vitro, further experiments were conducted to investigate the effects of selenite in vivo. Four-week-old female nude mice were injected with NB4 cells. Once tumors were detectable, mice were randomly divided into two groups and treated with selenite every 2 days $(3 \mathrm{mg} / \mathrm{kg} /$ day). After treatment with selenite for 3 weeks, mice were killed for analysis. A TUNEL assay and H\&E staining indicated that selenite-treated tumor tissues exhibited more dead cells than tissues from untreated mice.

As CD33 is a leukemic disease marker, we indirectly labeled CD33-positive cells in spleen and liver tissue sections. Immunohistochemical staining results indicated that there were many CD33-positive cells in tissues of control group and that these cells decreased after selenite treatment (Figure 5a). These results suggest that selenite has a therapeutic effect in vivo. We also investigated whether mechanisms of selenite activity in vivo were consistent with those that we described in vitro. Whole-tissue cell lysates were extracted, and western blot analysis indicated that the JNK/ATF2 axis, cyclin D1, CDK4, cyclin A, phospho-Rb, PARP and caspase-3 were altered in a similar manner as previously described in vitro (Figure 5b). Finally, these proteins were indirectly labeled with primary antibodies, and immunohistochemical staining results also indicated that these proteins were altered in the same manner as shown in vitro (Figure $5 \mathrm{c}$ ).

Figure 3 The JNK/ATF2 axis regulated selenite-induced cell cycle arrest and apoptosis. (a) JNK interacted with ATF2. Cells were exposed to $20 \mu \mathrm{M}$ selenite for $24 \mathrm{~h}$, and immunoprecipitation was used to detect interactions between these proteins. (b) The colocalization of JNK and ATF2 was reduced after selenite exposure. Cells were treated with $20 \mu \mathrm{M}$ selenite for $24 \mathrm{~h}$, and JNK and ATF2 were indirectly labeled with their unique primary antibodies. The images were generated with a confocal microscope. Bar represented $10 \mu \mathrm{m}$. (c and f) Inhibition of ATF2 further decreased the levels of cell cycle-related proteins and enhanced the extent of apoptosis induced by selenite. Cells were pretreated with $10 \mu \mathrm{M} \mathrm{SP} 600125$ for $1.5 \mathrm{~h}$ or transfected with siRNA to knock down ATF2. After cells were treated with $20 \mu \mathrm{M}$ selenite for $24 \mathrm{~h}$, the levels of cell cycle-related proteins, phospho-ATF2 and apoptosis markers were detected by western blot. (d, e, $\mathbf{g}$ and $\mathbf{h}$ ) Inhibition of ATF2 further enhanced the degree of apoptosis induced by selenite. Cells were pretreated with $10 \mu \mathrm{M} \mathrm{SP} 600125$ for $1.5 \mathrm{~h}$ or transfected with siRNA to knock down ATF2 and then treated with $20 \mu \mathrm{M}$ selenite for another $24 \mathrm{~h}$. The apoptotic and necrotic cells were measured with flow cytometric analysis or TUNEL assay. Data were represented as the mean \pm S.D. Bar: $100 \mu \mathrm{m}$. ${ }^{*} P<0.05$. (i) The overexpression of constitutively active JNK reversed selenite-induced apoptosis and the decrease in cell cycle-related protein expression. After transfection with constitutively active JNK plasmids, cells were treated with $20 \mu \mathrm{M}$ selenite for $24 \mathrm{~h}$. The levels of cell cycle-related proteins, phospho-ATF2 and markers of apoptosis were detected by western blot. ( $\mathrm{j}$ and $\mathbf{k}$ ) Overexpression of constitutively active JNK rescued selenite-induced apoptosis. Cells were transfected with constitutively active JNK plasmids and treated with $20 \mu \mathrm{M}$ selenite for $24 \mathrm{~h}$. The apoptotic and necrotic cells were measured with flow cytometry or TUNEL assay. Data are represented as the mean \pm S.D. Bar: $100 \mu$ m. ${ }^{\star} P<0.05$ 
a
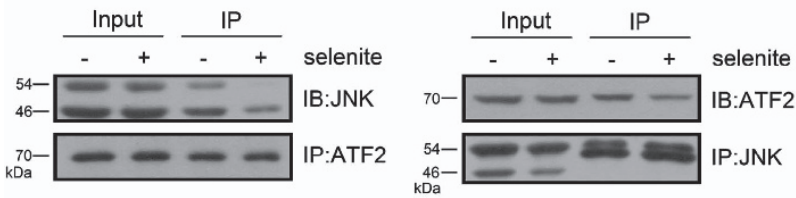

b

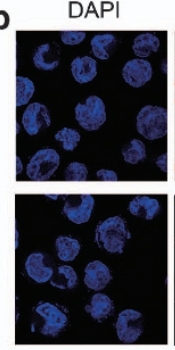

C

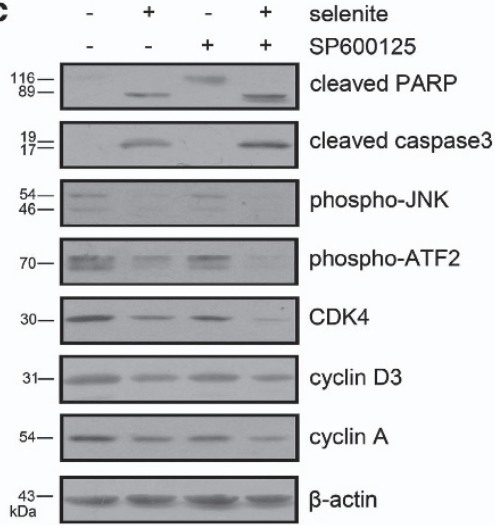

f

f $-+\quad+\quad+$ selenite

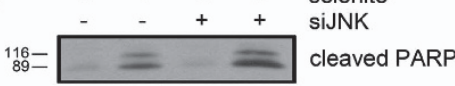

${ }_{17}=\square \square \square$ cleaved caspase3 ${ }_{46-}^{54-} \equiv \equiv \equiv \mathrm{JNK}$

${ }_{46}^{54}=\ldots \ldots$ phospho-JNK

${ }^{70-}=-\quad$ phospho-ATF2

${ }^{30-}-\ldots$ CDK4

$31-\square$ cyclin D3

${ }^{54-} \square-\square$ cyclin A

${ }_{\mathrm{kDa}}^{43-}=-\infty$-actin

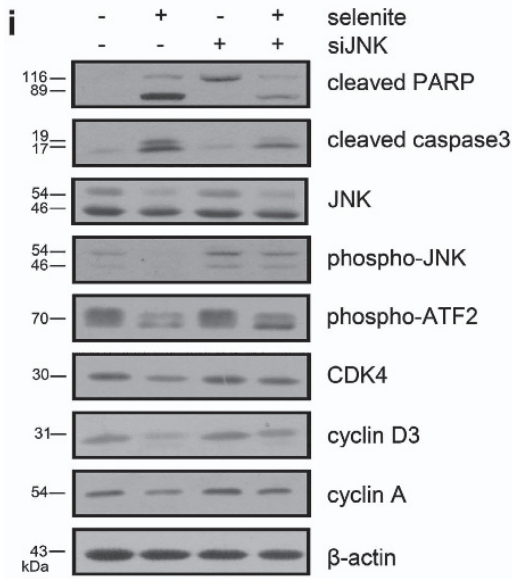

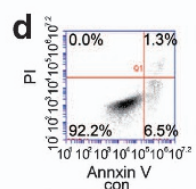
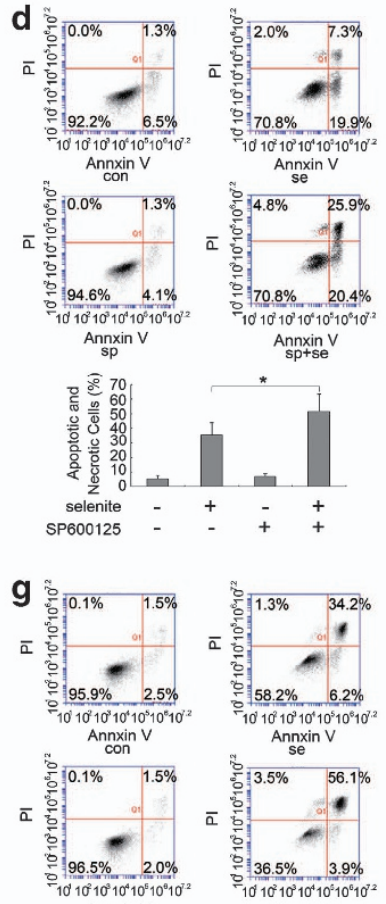
$\underset{\text { AnjXNR V }}{\text { SiJN }}$ Annxinv
sinN + se
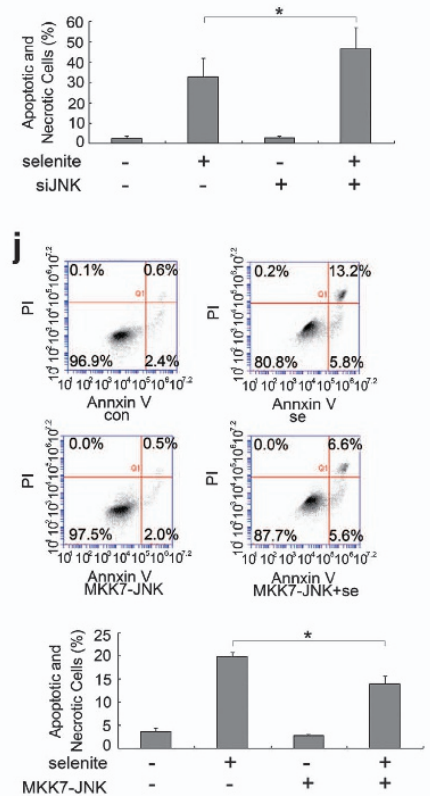

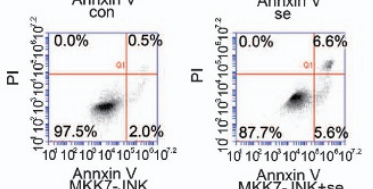

JNK

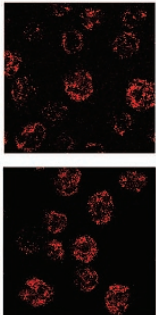

ATF2
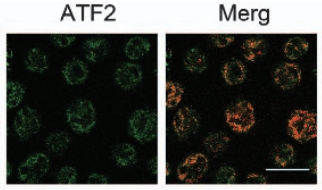

Large
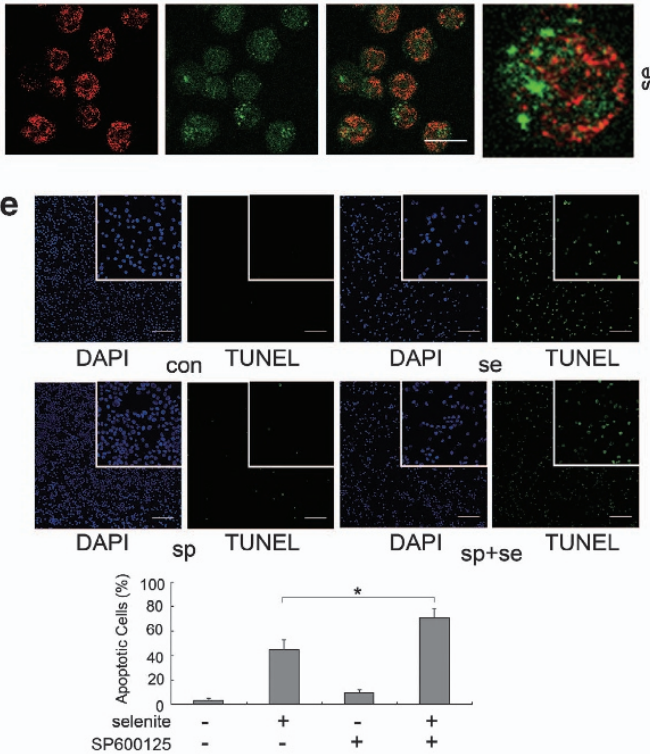

h
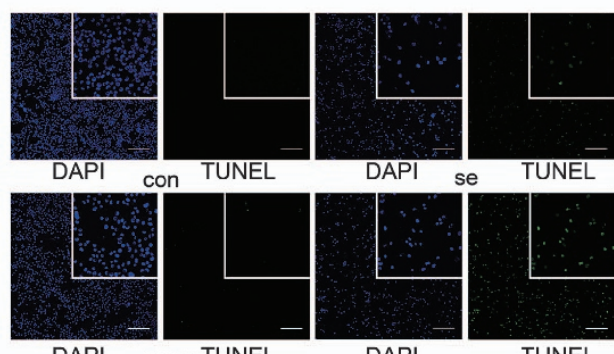

DAPI siJNK TUNEL
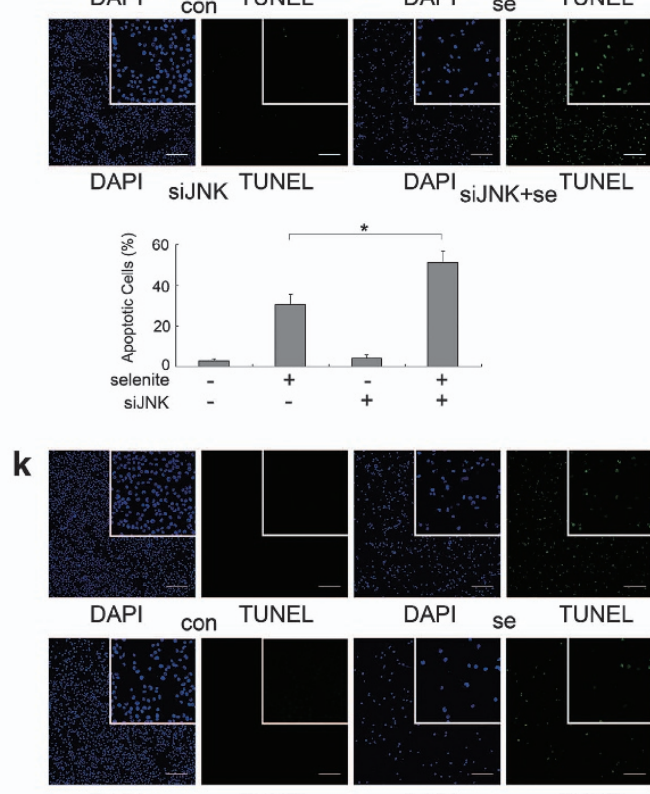

DAPI

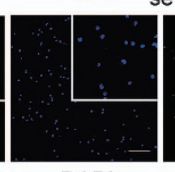

DAPI MKK7-JNK+se

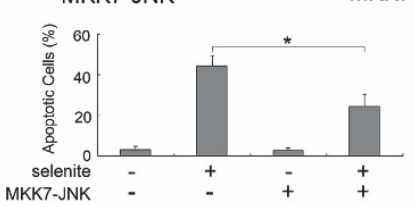


a

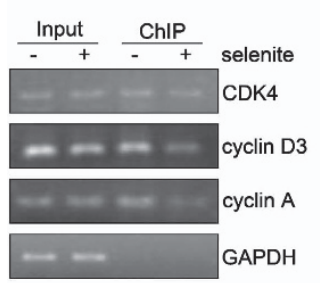

b

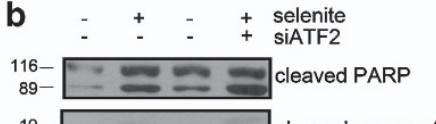

${ }_{17}^{19-}$

${ }_{70-}-\ldots$ -

70- $= \pm=$ phoapho-ATF2

${ }_{30}--\square \mathrm{CDK} 4$

31-

54- - - - cyclin A

$110-2$ phospho-Rb

43- $=-\infty-a c t i n$ c
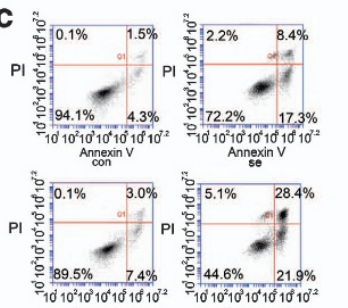

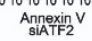

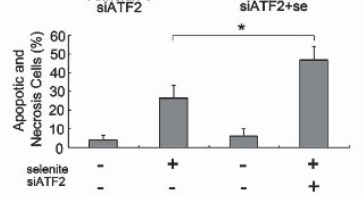

d
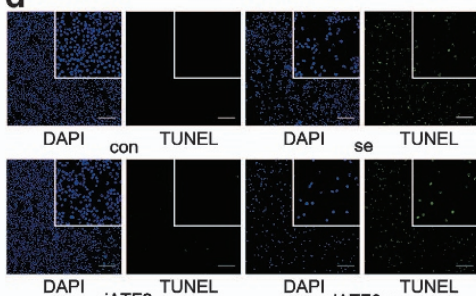

DAPI $_{\text {SiATF2 } 2 \text { TUNEL DAPI }}$ TUNEL

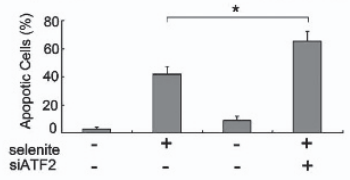

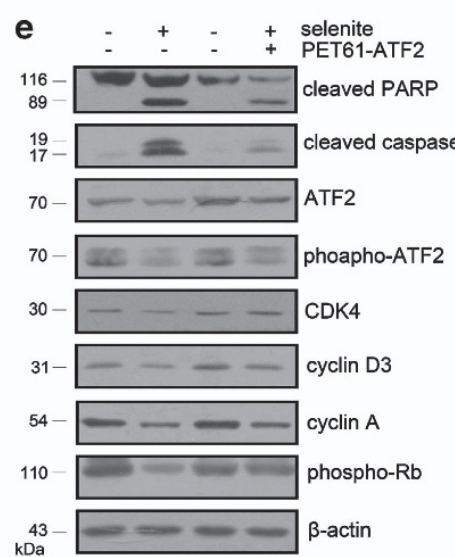

h

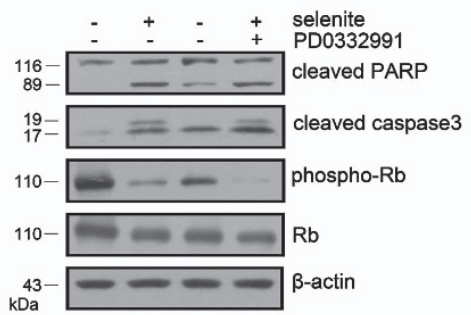

f

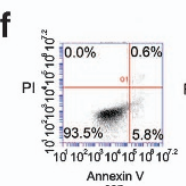

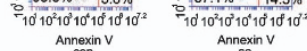

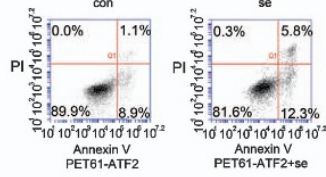

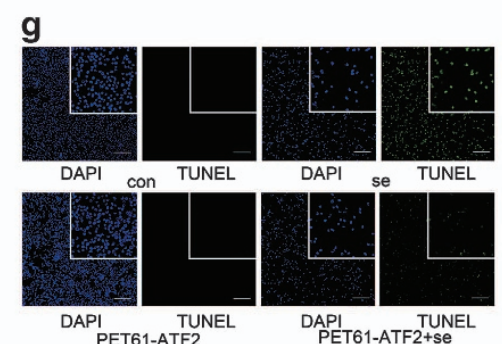
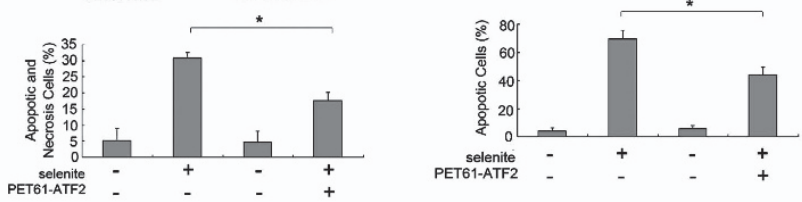

i
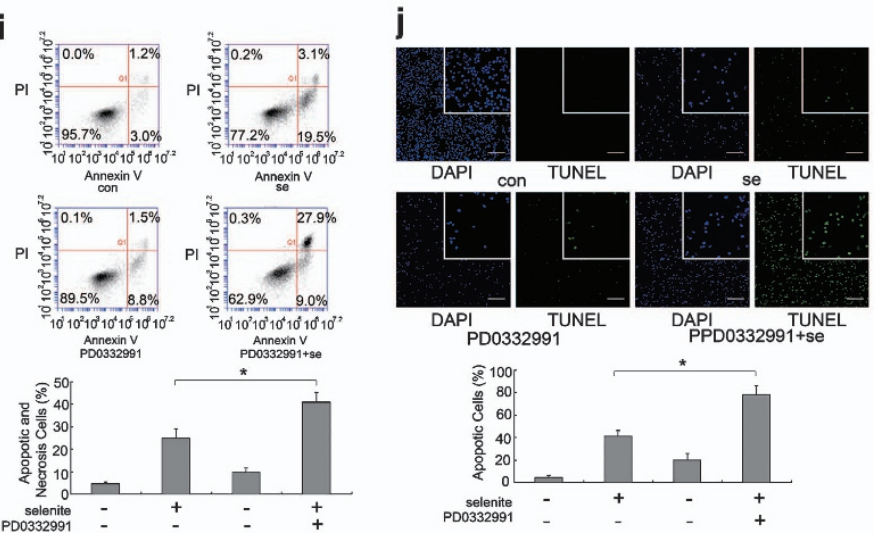

Figure 4 ATF2 regulated cell cycle-related protein expression and inhibited apoptosis in selenite-treated NB4 cells. (a) ATF2 bound to the promoters of cyclin D3, cyclin A and CDK4. A ChIP assay was performed as described above. GAPDH was used as a loading control for the input sample and a negative control in the ChIP sample. (b) Inhibition of ATF2 expression further reduced the levels of cell cycle-related proteins and increased the cleavages of caspase-3 and PARP compared with selenite treatment alone. After transfection with siRNA targeting ATF2, cells were treated with $20 \mu \mathrm{M}$ selenite. Levels of cyclin D3, cyclin A, CDK4, cleaved caspase-3 and cleaved PARP were detected by western blot. (c and $\mathbf{d}$ ) Inhibition of ATF2 expression resulted in enhanced apoptosis. Cells were transfected with siRNA targeting ATF2 and treated with $20 \mu \mathrm{M}$ selenite. The apoptotic and necrotic cells were measured with flow cytometry or TUNEL assay. Data were represented as the mean \pm S.D. Bar: $100 \mu$ m. ${ }^{*} P<0.05$. (e) Overexpression of ATF2 reversed selenite-induced apoptosis and the decreased cell cycle-related protein expression. After transfection with ATF2 overexpression plasmids, cells were treated with $20 \mu \mathrm{M}$ selenite. Levels of CDK4, cyclin D3, cyclin A, cleaved caspase-3 and cleaved PARP were detected by western blot. (f and $\mathbf{g}$ ) ATF2 overexpression rescued selenite-induced apoptosis. Cells were transfected with PET61-ATF2 plasmids and exposed to $20 \mu \mathrm{M}$ selenite for $24 \mathrm{~h}$. The apoptotic and necrotic cells were assessed with flow cytometry or TUNEL assay. Data were represented as the mean \pm S.D. Bar: $100 \mu \mathrm{m}$. ${ }^{*} P<0.05$. (h) Inhibition of CDK4 further enhanced selenite-induced cell cycle arrest and apoptosis. Cells were pretreated with $2.5 \mu \mathrm{M}$ PD0332991 for $1 \mathrm{~h}$ before selenite exposure. Levels of cleaved caspase-3, cleaved PARP and phospho-Rb were detected by western blot. (i and $\mathrm{j}$ ) Inactivation of CDK4 further enhanced the extent of selenite-induced apoptosis. Data are represented as the mean \pm S.D. Bar: $100 \mu \mathrm{m}$. ${ }^{*} P<0.05$

\section{Discussion}

Selenite has been shown to have therapeutic effects on a wide range of cancer cells. ${ }^{20-22}$ Some studies have indicated that selenite levels in the nutritional range can inhibit apoptosis, whereas this element induced apoptosis at levels in the supernutritional range. ${ }^{23}$ Our previous study also showed that selenite had an effect on cancer cells in in vitro experiments, 
a

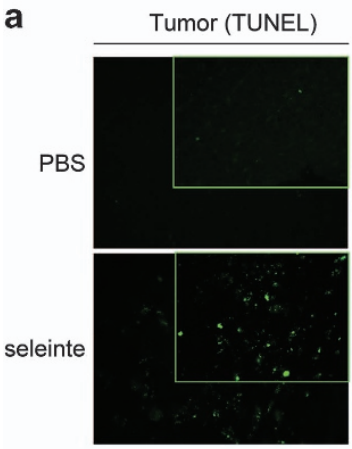

C

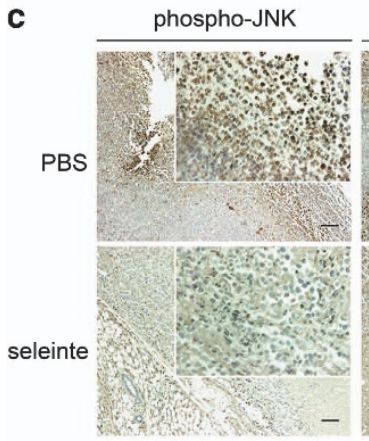

Tumor (HE)

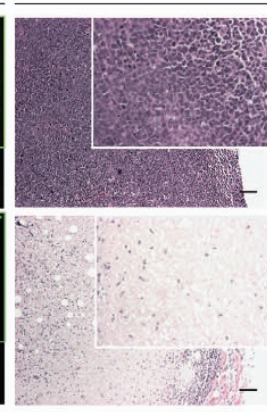

phospho-ATF2

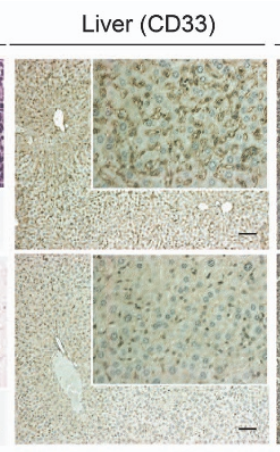

CDK4

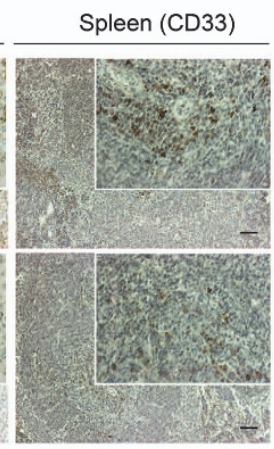

b

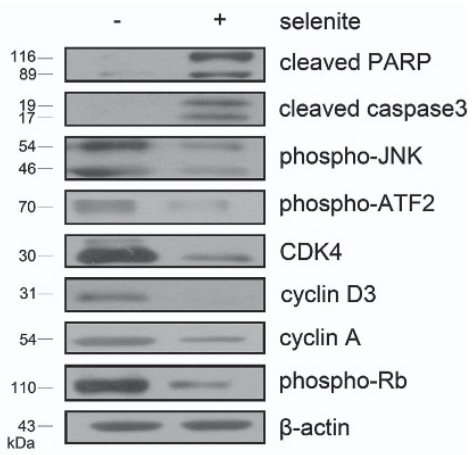

cyclin A

phospho-Rb
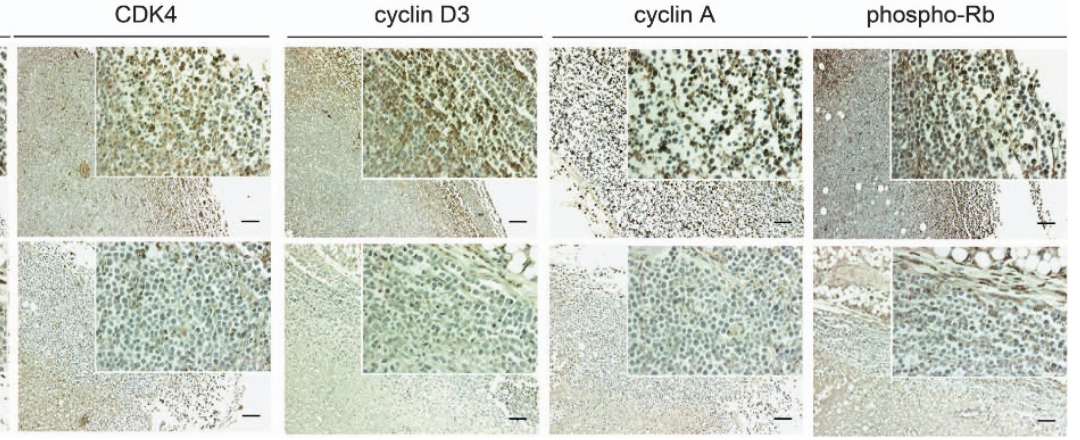

Figure 5 The JNK/ATF2 axis was altered by selenite in vivo. (a) Selenite had therapeutic effects in vivo. H\&E and TUNEL staining were performed to detect dead cells. CD33-positive cells in spleen and liver tissue sections were indirectly labeled. The images were visualized with a Zeiss microscope (Jena, Germany). Bar: $100 \mu$ m. (b) The JNK/ATF2 axis is altered in vivo. Whole-cell lysates were extracted, and levels of phospho-JNK, phospho-ATF2, phospho-Rb, cyclin A, CDK4, cyclin D3, cleaved caspase-3 and cleaved PARP were detected by western blot. (c) The JNK/ATF2 axis was altered by selenium treatment, similar to the effect seen in vitro. phospho-JNK, phospho-ATF2, phospho-Rb, cyclin A, CDK4, cyclin D3, cleaved caspase-3 and cleaved PARP were indirectly labeled. The images were visualized with a Zeiss microscope. Bar: $100 \mu \mathrm{m}$

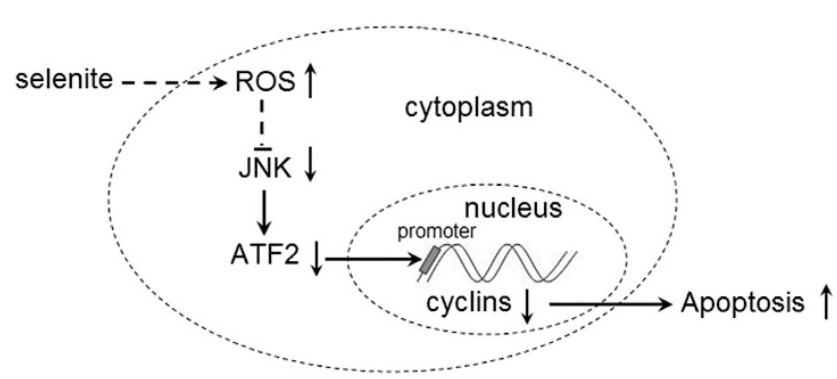

Figure 6 Selenite-inducedROSinhibited the activity of JNK,S which further caused dephosphorylation of ATF2, a transcriptional factor of some cell cyclerelated proteins such as Cylin A, Cyclin D3 and CDK4. As a result, NB4 cells were arrested at G0/G1 phase and finally underwent an obvious apoptosis progression. After selenite exposure, ROS was arisen rapidly, which further inhibited JNK/ATF2 axis. The inactivation of ATF2 resulted in the decreased affinity of this transcriptional factor for the promoters of cyclin A, cyclin D3 and CDK4, which in turn led NB4 cells to be arrested at G0/G1 phase and undergo apoptosis

exhibited apparent therapeutic effects in vivo and reduced toxicity against normal cells compared with tumor cells. ${ }^{24}$ Therefore, studies exploring the mechanisms by which selenite induced cell death were necessary. The current study explored whether super-nutritional levels of selenite had toxic effects on leukemic NB4 cells in vitro and in vivo. First, selenite induced ROS production and inhibited the phosphorylation of JNK. This inhibition of JNK activation caused dephosphorylation of the transcription factor ATF2. As ATF2 had high affinity for the promoter sequences of the cell cycle-related proteins including cyclin A, CDK4 and cyclin D3, the reduced expression of phosphorylated ATF2 led NB4 cells to be arrested at G0/G1 phase and therefore underwent apoptosis. This study explored the mechanisms by which selenite induced apoptosis in NB4 cells.

Progression through the cell cycle is an energy-demanding process and includes several organized events to allow one cell divide into two daughter cells. The cell cycle contains G0, G1, S, G2 and M phases. Cell cycle transitions from one phase to the next require regulatory mechanisms called checkpoints. CDK/cyclin complexes are often involved in these checkpoints. ${ }^{25,26}$ In the present study, we showed that selenite arrested NB4 cells at G0/G1 phase by inhibiting the expression of cyclin D1, cyclin D3, CDK 4 and cyclin A. Cells at the G0/G1 checkpoint are surveyed to determine whether their DNA replicates correctly, and these cells will not transition to the next phase until replication problems are solved. If DNA repair does not occur after some time, cells will undergo apoptosis. This study also showed that selenite induces cell cycle arrest along with the inhibition of DNA synthesis, further leading to apoptosis in NB4 cells. This appeared to be the mechanism by which selenite exerted therapeutic effects on leukemia NB4 cells.

ROS are upstream regulatory factors thought to be involved in many types of chemical-induced apoptosis. In the past, ROS have been shown to be involved in regulating seleniteinduced apoptosis, while the exact mechanisms of this regulation are not well understood. In this study, we showed that the level of hydrogen peroxide, an intracellular ROS, 
rose rapidly following selenite treatment and that scavenging this ROS could inhibit the effects of selenite on cell cycle arrest. This is the first demonstration that ROS arrest cells in the G0/G1 phase by inhibiting the JNK/ATF2 axis.

ATF2 is a cAMP response element binding family member. The upstream kinase that acts on ATF2 may be JNK/SAPK, p38 MAPK or ERK depending on the cell type and the type of stimulation. In the past, ATF2 was known as an oncoprotein that had anti-apoptotic function and was a cancer therapy target. $^{26}$ The pro-survival function of ATF2 was dependent on its nuclear localization, and ATF2 in the nucleus could interact with other transcription factors, such as C-Jun, and formed heterodimers to promote the expression of pro-survival proteins including $\mathrm{Bcl}-\mathrm{xL}, \mathrm{CDK} 4$ and cyclin D. ${ }^{27-30}$ However, ATF2 in the nucleus had other functions, including chromatin remodeling and DNA repair, that were not dependent on its transcriptional activity. For example, ATM could phosphorylate ATF2 at Ser490 and Ser498 and further regulated DNA repair, while the mutation of ATF2 at Ser490 and Ser498 resulted in the destabilization of the genome. ${ }^{25,31}$

Recently, the role of cytoplasmic ATF2 has been explored. It has been shown that translocation of ATF2 from the nucleus to the cytoplasm will result in the inhibition of ATF2 nuclear pro-survival function. However, some reports have demonstrated that $\mathrm{PKC} \varepsilon$ phosphorylates ATF2 at T52 and therefore causes its nuclear export. Thereafter, ATF2 would localize to the outer mitochondrial membrane where it could interact with HK1 and VDAC, further causing alterations in mitochondrial permeability and apoptosis. ${ }^{32}$ The pro-apoptotic role of ATF2 is related to its transcriptional activity in some cancer cells. ATF2 has been shown to directly bind to the promoter of Hrk and induce apoptosis via Hrk upregulation. ${ }^{33}$ In this study, we found that the phosphorylation of ATF2 decreased in the nucleus following selenite treatment and that this decrease was dependent on the inactivation of JNK/SAPK. Further experiments indicated that ATF2 regulated cell cycle progression by binding to the promoters of some cell cycle-related proteins and therefore regulating their transcription.

Taken together, our study showed that selenite induced ROS generation, which in turn inhibited the JNK/ATF2 axis and further downregulated the expression of cell cycle-related proteins. NB4 cells treated with selenite were arrested in the G0/G1 phase and underwent apoptosis. Finally, in vivo experiments demonstrated that selenite had therapeutic effects on tumors and regulated the JNK/ATF2 axis as it did in vitro. As shown in Figure 6, this study explored the mechanisms by which selenite induced apoptosis and the role of ROS in regulating cell cycle progression.

\footnotetext{
Materials and Methods

Chemicals and antibodies. Sodium selenite and an anti- $\beta$-actin antibody were purchased from Sigma-Aldrich (St. Louis, MO, USA). PD0332991 was purchased from Selleck Chemicals (Houston, TX, USA). SP600125 and MnTMPyP were purchased from Merck Calbiochem (San Diego, CA, USA). The pCDNA3-JNK vector was obtained from Addgene (www.addgene.org), and the PET61-ATF2 vector was a kind gift from Drs. Ronai and Lau. The antibodies reacting with cleaved PARP, cleaved caspase-3, JNK, phospho-JNK, ATF2, phospho-ATF2, CDK4, cyclin D3, cyclin A, Rb and phospho-Rb that were used for western blotting were obtained from Cell Signaling Technology (Danvers, MA, USA). For immunohistochemical staining, an anti-CD33 antibody was purchased from BIOSS, and anti-phospho-JNK, anti-phospho-ATF2 and anti-phospho-Rb antibodies
}

were purchased from Cell Signaling Technology, while anti-CDK4, anti-cyclin D3 and anti-cyclin A antibodies were purchased from Santa Cruz Biotechnology (Santa Cruz, CA, USA). HRP-conjugated anti-mouse and anti-rabbit secondary antibodies were purchased from ZSGB-BIO (Beijing, China). FITC-conjugated anti-mouse and Cy3-conjugated anti-rabbit antibodies were purchased from Jackson Laboratories (Amritsar, India).

Cell culture. NB4 cells were cultured in RPMI-1640 medium containing $10 \%$ FCS, $100 \mathrm{U} / \mathrm{ml}$ penicillin and $100 \mu \mathrm{g} / \mathrm{ml}$ streptomycin at $37^{\circ} \mathrm{C}$ and $5 \% \mathrm{CO}_{2}$ in a humidified atmosphere.

Detection of apoptosis with annexin V-FITC/PI staining. Cells were collected and labeled with Annexin V/PI in $1 \times$ binding buffer for $15 \mathrm{~min}$. The apoptotic and necrotic cells were detected with flow cytometry. The sum of the Annexin $\mathrm{V}^{+} / \mathrm{PI}^{-}$and Annexin $\mathrm{V}^{+} / \mathrm{PI}^{+}$populations was defined as the total number of apoptotic and necrotic cells.

DNA synthesis analysis using BrdU-PI staining. Cells were pulselabeled with $20 \mu \mathrm{M} \mathrm{BrdU}$ under normal culture conditions in the dark for $30 \mathrm{~min}$, collected by centrifugation at 2500 r.p.m. for 5 min, washed twice with ice-cold PBS and pipetted into ice-cold $70 \%$ ethanol for fixation at $-20^{\circ} \mathrm{C}$ for $30 \mathrm{~min}$. Fixed cells were then collected by centrifugation at 2500 r.p.m. for 5 min, washed with ice-cold PBS and resuspended in $3 \mathrm{M} \mathrm{HCl}$ for denaturation at room temperature for $20 \mathrm{~min}$. Collected cells were then treated with $0.1 \mathrm{M}$ borax buffer $(0.1 \mathrm{~mol} / \mathrm{l}$ sodium borate, $\mathrm{pH} 8.5)$ for $10 \mathrm{~min}$ to terminate the denaturing process; cells were then collected, washed with PBS and treated with $0.5 \%$ Triton X-100 for $10 \mathrm{~min}$ at room temperature. Cells were again collected, washed with PBS and incubated with $100 \mu \mathrm{l}$ of diluted FITC-conjugated antibody against BrdU $(5 \mu \mathrm{l}$ antibody diluted in $95 \mu \mathrm{l}$ PBS containing $0.5 \%$ Tween-20 and $0.5 \%$ BSA) at room temperature for $1 \mathrm{~h}$ with occasional agitation. After the antibody solution was removed by centrifugation at 2500 r.p.m., the cells were treated with RNase $A$ and stained with $\mathrm{PI}$ as described above, and were finally subjected to flow cytometry analysis. FITC-positive cells were considered to be actively synthesizing DNA.

Cell cycle analysis by flow cytometry. For cell cycle analysis with PI staining, $\sim 10^{6}$ cells were collected with centrifugation at 2500 r.p.m. for $5 \mathrm{~min}$, washed twice with ice-cold PBS, resuspended in $0.5 \mathrm{ml} \mathrm{PBS}$ and pipetted into cold $70 \%$ ethanol for fixation at $4{ }^{\circ} \mathrm{C}$ for at least $12 \mathrm{~h}$. Fixed cells were then collected through centrifugation at 2500 r.p.m. for 5 min, washed with ice-cold PBS and resuspended in $0.5 \mathrm{ml}$ PBS containing $50 \mu \mathrm{g} / \mathrm{ml}$ RNase A. The system was incubated at $37^{\circ} \mathrm{C}$ for $30 \mathrm{~min}$ and then placed on ice to stop the reaction. PI solution was then added to achieve a final concentration of $50 \mu \mathrm{g} / \mathrm{ml}$, and cells were stained for at least $30 \mathrm{~min}$ on ice in the dark. The resulting cell suspension was then subjected to flow cytometry analysis.

Western blotting. For western blots, $\sim 1 \times 10^{6}$ cells were collected and washed twice with ice-cold PBS. RIPA lysis buffer $(20 \mathrm{nM}$ Tris, pH 7.5; $1 \mathrm{mM}$ EDTA; $1 \mathrm{mM}$ EGTA; $150 \mathrm{mM} \mathrm{NaCl}$; $1 \%$ Triton $\mathrm{X}-100 ; 2.5 \mathrm{mM}$ sodium pyrophosphate; $1 \mathrm{mM} \beta$-glycerol phosphate; $1 \mathrm{mM} \mathrm{Na}_{3} \mathrm{VO}_{4} ; 1 \mathrm{mM} \mathrm{PMSF}$ and $1 \mu \mathrm{g} / \mathrm{ml}$ leupeptin) was added to the cell pellet and cells were ultrasonicated on ice. The lysate was then centrifuged at $12000 \times \mathrm{g}$ for $10 \mathrm{~min}$ at $4{ }^{\circ} \mathrm{C}$, and supernatants were collected and separated with SDS-PAGE. The proteins were then transferred to a nitrocellulose membrane, and the membrane was blocked and washed. The membrane was then incubated with primary antibody at $4{ }^{\circ} \mathrm{C}$ for $\sim 12 \mathrm{~h}$ and labeled with HRP-conjugated secondary antibodies for $2 \mathrm{~h}$ at room temperature. Finally, the membranes were washed and probed with SuperSignal chemiluminescent substrate (PerkinEImer, Waltham, MA, USA).

Measurement of ROS production. Intracellular ROS production was measured by the oxidant-specific fluorescent probe DCFH-DA. Approximately $10^{7}$ cells were collected after treatment with selenite or other chemical combinations. The cells were resuspended in serum-free culture medium that contained the DCFH-DA probe. The cells were then incubated at $37^{\circ} \mathrm{C}$ for $30 \mathrm{~min}$. After incubation, the cells were washed twice using cold PBS and resuspended in PBS, and fluorescence intensity was measured by excitation at $502 \mathrm{~nm}$ and emission at $530 \mathrm{~nm}$.

SiRNA interference. Approximately $10^{6}$ cells were harvested and washed with Opti-MEM medium. Lipofectamine 2000 (Invitrogen, Carlsbad, CA, USA) and 
an siRNA targeting either ATF2 (5'-GGAGCCUUCUGUUGUAGAAUU-3') or JNK (5'-GCCCAGTAATATAGTAGTA-3') were mixed for $25 \mathrm{~min}$. After transfection with this mixture for $\sim 6 \mathrm{~h}$, cells were treated with $20 \mu \mathrm{M}$ selenite for an additional $24 \mathrm{~h}$. The negative control and targeting siRNA were obtained from GenePharma.

Immunoprecipitation. Approximately $10^{7}$ cells were lysed with RIPA buffer on ice for $30 \mathrm{~min}$. Next, $200 \mu \mathrm{g}$ of the lysate was mixed with a suitable amount of either the ATF2 antibody or the JNK antibody and rotated at $4{ }^{\circ} \mathrm{C}$ overnight, while the remainder of the lysate was kept as the input sample. After the overnight incubation, this solution was mixed with protein $A+G$ and rotated for $3 \mathrm{~h}$ at $4{ }^{\circ} \mathrm{C}$, and then the samples were washed three times with RIPA buffer. Finally, the pellets were resuspended with $3 \times$ SDS loading buffer and boiled for $\sim 10 \mathrm{~min}$ The samples were then centrifuged briefly, and the supernatants were collected.

Chromatin immunoprecipitation. A Simple ChIP Enzymatic Chromatin IP Kit was purchased from Cell Signaling Technology. Approximately $10^{6}$ cells were crosslinked with formaldehyde for $10 \mathrm{~min}$, and this process was terminated with glycine at a final concentration of $0.125 \mathrm{M}$. To extract the nuclear fraction, the sample was then lysed with buffer $A$ on ice for $\sim 10 \mathrm{~min}$. Next, the samples were incubated with buffer $B$, and then the lysates were digested with micrococcal nuclease. This process was stopped with 0.5 M EDTA. The samples were then centrifuged at 13000 r.p.m. for $10 \mathrm{~min}$ at $4{ }^{\circ} \mathrm{C}$, and the pellets were resuspended and incubated with P73 antibody overnight at $4{ }^{\circ} \mathrm{C}$. Furthermore ChIP-grade protein $G$ agarose beads were added, and the mixture was rotated for $\sim 3 \mathrm{~h}$ at $4^{\circ} \mathrm{C}$. Finally, the DNA was eluted. Primers for GAPDH (sense: $5^{\prime}$-TACTAGC GGTTTTACGGGCG-3', anti-sense: $5^{\prime}$-TCGAACAGGAGGAGCAGAGAGCGA-3'), CDK4 (sense: 5'-ATGCAGACAGGCTGAAAGAC-3', anti-sense: 5'-GATGGCA GCCACGTGATCTG-3'), cyclin D3 (sense: $5^{\prime}$-TTCGGGCACTTGACCTTA-3', antisense: $5^{\prime}$-GGCCGATTTCTTGACTCTTA-3') and cyclin A (sense: $5^{\prime}$-TGTGC GAGCGGTCTACTG-3', anti-sense: $5^{\prime}$-CGCAGACTCAAAGCGTGA-3') that recognized the ATF2 binding site of each promoter were generated by Sangon Biotech (Shanghai, China).

Xenograft tumor model. Four-week-old female nude mice were injected with NB4 cells. After tumors were detectable, mice were randomly divided into two groups (each group contained five mice) and treated with selenite every 2 days $(3 \mathrm{mg} / \mathrm{kg} / \mathrm{day})$. After treatment with selenite for $\sim 3$ weeks, mice were killed for analysis. The animals were maintained in accordance with the Declaration of Helsinki and the NIH Guide for the Care and Use of Laboratory Animals.

TUNEL assay for cultured cells. NB4 cells were harvested and then transferred to the slides. Being fixed with $4 \%$ paraformdehyde and permeabilized with $0.1 \%$ Triton X-100, slides were washed twice with PBS and incubated with TUNEL detecting buffer for $60 \mathrm{~min}$ at $37^{\circ} \mathrm{C}$. Finally, the slides were washed three times and mounted with anti-fade medium. The images were visualized with a confocal microscope.

TUNEL assay for tissue. A FragEL DNA Fragmentation Detection Kit was purchased from Merck. After being deparaffinized and hydrated, the slides were washed with $1 \times$ TBS for $2 \mathrm{~min}$ and incubated with $20 \mu \mathrm{g} / \mathrm{ml}$ proteinase $\mathrm{K}$ for $20 \mathrm{~min}$. After a second round of washes, slides were incubated with $1 \times \mathrm{TdT}$ buffer for an additional $30 \mathrm{~min}$ at room temperature. Subsequently, the tissues were also treated with $57 \mu \mathrm{l}$ mix buffer and $3 \mu \mathrm{l} \mathrm{TdT} \mathrm{enzyme} \mathrm{for} 1 \mathrm{~h}$ at $37^{\circ} \mathrm{C}$. Finally, the slides were washed and mounted with mounting medium.

H\&E staining. Following a hydration process, the tissues were stained with Harris hematoxylin for $15 \mathrm{~min}$. After being washed for $3 \mathrm{~min}$, the slides were immersed in $1 \%$ hydrochloric acid in $75 \%$ ethanol for $30 \mathrm{~s}$. Before dehydration, the tissues were stained with eosin for $10 \mathrm{~min}$. Finally, the slides were immersed in xylene and mounted with mounting medium.

Immunohistochemical staining. After being deparaffinized and dehydrated, the slides were washed with running water for $2 \mathrm{~min}$. Endogenous peroxidase activity was blocked with $3 \%$ hydrogen peroxide in methanol. The slides were then washed three times, and the tissues were incubated with primary antibodies overnight at $4{ }^{\circ} \mathrm{C}$. After a second round of washes, the slides were incubated with secondary antibodies at room temperature for $2 \mathrm{~h}$ and treated with DAB. Next, the nuclei were stained with Mayer's hematoxylin for $2 \mathrm{~min}$. Slides were then dehydrated and clarified with xylene. Finally, the slides were mounted with mounting medium.
Statistical analysis. Values are represented as the mean \pm S.D. Two-tailed Student's $t$-tests were performed for comparisons of two groups. A $P$-value of $P<0.05$ was considered significant.

\section{Conflict of Interest}

The authors declare no conflict of interest.

Acknowledgements. We thank Ms Pan Lin for her expertise in IHC. This work was supported by the National Natural Science Foundation of China (grant no: 31170788, 31340037), the National Natural Science Foundation for Young Scholars of China (grant no: 31101018), the Natural Science Foundation of Beijing (grant no: 5082015), the Research Fund for the Doctoral Program of Higher Education of China (grant no: 20091106110025) and the National Laboratory Special Fund (grant no: 2060204).

1. Kakizuka A, Miller Jr WH, Umesono K, Warrell Jr RP, Frankel SR, Murty VV et al. Chromosomal translocation $t(15 ; 17)$ in human acute promyelocytic leukemia fuses RAR alpha with a novel putative transcription factor, PML. Cell 1991; 66: 663-674.

2. Lanotte M, Martin-Thouvenin V, Najman S, Balerini P, Valensi F, Berger R. NB4, a maturation inducible cell line with $t(15 ; 17)$ marker isolated from a human acute promyelocytic leukemia (M3). Blood 1991; 77: 1080-1086.

3. Meyer PN, Roychowdhury S, Kini AR, Alkan S. HSP90 inhibitor 17AAG causes apoptosis in ATRA-resistant acute promyelocytic leukemia cells. Leuk Res 2008; 32 . 143-149.

4. Zuo L, Li J, Yang Y, Wang X, Shen T, Xu CM et al. Sodium selenite induces apoptosis in acute promyelocytic leukemia-derived NB4 cells by a caspase-3-dependent mechanism and a redox pathway different from that of arsenic trioxide. Ann Hematol 2004; 83: $751-758$

5. Shen ZX, Shi ZZ, Fang J, Gu BW, Li JM, Zhu YM et al. All-trans retinoic acid/As2O3 combination yields a high quality remission and survival in newly diagnosed acute promyelocytic leukemia. Proc Natl Acad Sci USA 2004; 101: 5328-5335.

6. Shi K, Jiang Q, Li Z, Shan L, Li F, An J et al. Sodium selenite alters microtubule assembly and induces apoptosis in vitro and in vivo. J Hematol Oncol 2013; 6: 7.

7. Dong $\mathrm{H}$, Ying T, Li T, Cao T, Wang J, Yuan J et al. Comparative proteomic analysis of apoptosis induced by sodium selenite in human acute promyelocytic leukemia NB4 cells. J Cell Biochem 2006; 98: 1495-1506.

8. Han B, Wei W, Hua F, Cao T, Dong H, Yang T et al. Requirement for ERK activity in sodium selenite-induced apoptosis of acute promyelocytic leukemia-derived NB4 cells. J Biochem Mol Biol 2007; 40: 196-204.

9. Jiang Q, Wang Y, Li T, Shi K, Li Z, Ma Y et al. Heat shock protein 90-mediated inactivation of nuclear factor-kappaB switches autophagy to apoptosis through becn1 transcriptional inhibition in selenite-induced NB4 cells. Mol Biol Cell 2011; 22: 1167-1180.

10. Caffrey PB, Frenkel GD. Sensitivity of melphalan-resistant tumors to selenite in vivo. Cancer Lett 1997; 121: 177-180.

11. Li Z, Shi K, Guan L, Cao T, Jiang Q, Yang Y et al. ROS leads to MnSOD upregulation through ERK2 translocation and p53 activation in selenite-induced apoptosis of NB4 cells. FEBS Lett 2010; 584: 2291-2297.

12. Huang F, Nie C, Yang Y, Yue W, Ren Y, Shang Y et al. Selenite induces redox-dependent Bax activation and apoptosis in colorectal cancer cells. Free Radic Biol Med 2009; 46: 1186-1196.

13. Guan L, Han B, Li Z, Hua F, Huang F, Wei W et al. Sodium selenite induces apoptosis by ROS-mediated endoplasmic reticulum stress and mitochondrial dysfunction in human acute promyelocytic leukemia NB4 cells. Apoptosis 2009; 14: 218-225.

14. Cao TM, Hua FY, Xu CM, Han BS, Dong H, Zuo L et al. Distinct effects of different concentrations of sodium selenite on apoptosis, cell cycle, and gene expression profile in acute promyeloytic leukemia-derived NB4 cells. Ann Hematol 2006; 85: 434-442.

15. Kristjansdottir K, Kim K, Choi JS, Horan TC, Brard L, Moore RG et al. 7 Methyl indole ethyl isothiocyanate causes ROS mediated apoptosis and cell cycle arrest in endometrial cancer cells. Gynecol Oncol 2012; 126: 252-258.

16. Lopez-Bergami P, Lau E, Ronai Z. Emerging roles of ATF2 and the dynamic AP1 network in cancer. Nat Rev Cancer 2010; 10: 65-76.

17. Zhang JY, Jiang $H$, Gao W, Wu J, Peng K, Shi YF et al. The JNK/AP1/ATF2 pathway is involved in $\mathrm{H} 2 \mathrm{O} 2$-induced acetylcholinesterase expression during apoptosis. Cell Mol Life Sci 2008; 65: 1435-1445.

18. Ouwens DM, de Ruiter ND, van der Zon GC, Carter AP, Schouten J, van der Burgt C et al. Growth factors can activate ATF2 via a two-step mechanism: phosphorylation of Thr71 through the Ras-MEK-ERK pathway and of Thr69 through RalGDS-Src-p38. EMBO J 2002; 21: 3782-3793.

19. Baan B, van der Zon GC, Maassen JA, Ouwens DM. The nuclear appearance of ERK1/2 and p38 determines the sequential induction of ATF2-Thr71 and ATF2-Thr69 phosphorylation by serum in JNK-deficient cells. Mol Cell Endocrinol 2009; 311 . $94-100$ 
20. Park SH, Kim JH, Chi GY, Kim GY, Chang YC, Moon SK et al. Induction of apoptosis and autophagy by sodium selenite in A549 human lung carcinoma cells through generation of reactive oxygen species. Toxicol Lett 2012; 212: 252-261.

21. Fang W, Han A, Bi X, Xiong B, Yang W. Tumor inhibition by sodium selenite is associated with activation of $\mathrm{C}$-Jun $\mathrm{NH} 2$-terminal kinase 1 and suppression of beta-catenin signaling. Int J Cancer 2010; 127: 32-42.

22. Li ZS, Shi KJ, Guan LY, Jiang Q, Yang Y, Xu CM. Downregulation of protein kinase Calpha was involved in selenite-induced apoptosis of NB4 cells. Oncol Res 2010; 19: 77-83.

23. Brozmanova J, Manikova D, VIckova V, Chovanec M. Selenium: a double-edged sword for defense and offence in cancer. Arch Toxicol 2010; 84: 919-938.

24. Li F, Jiang $Q$, Shi KJ, Luo H, Yang Y, Xu CM. RhoA modulates functional and physical interaction between ROCK1 and Erk1/2 in selenite-induced apoptosis of leukaemia cells. Cell Death Dis 2013; 4: e708.

25. Diaz-Moralli S, Tarrado-Castellarnau M, Miranda A, Cascante M. Targeting cell cycle regulation in cancer therapy. Pharmacol Ther 2013; 138: 255-271.

26. Barta T, Dolezalova D, Holubcova Z, Hampl A. Cell cycle regulation in human embryonic stem cells: links to adaptation to cell culture. Exp Biol Med (Maywood) 2013: 238: 271-275.

27. Salameh A, Galvagni F, Anselmi F, De Clemente C, Orlandini M, Oliviero S. Growth factor stimulation induces cell survival by c-Jun. ATF2-dependent activation of Bcl-XL. J Biol Chem 2010; 285: 23096-23104.

28. Xiao L, Rao JN, Zou T, Liu L, Yu TX, Zhu XY et al. Induced ATF-2 represses CDK4 transcription through dimerization with JunD inhibiting intestinal epithelial cell growth after polyamine depletion. Am J Physiol Cell Physiol 2010; 298: C1226-C1234.
29. Nakamura T, Okuyama S, Okamoto S, Nakajima T, Sekiya S, Oda K. Down-regulation of the cyclin A promoter in differentiating human embryonal carcinoma cells is mediated by depletion of ATF-1 and ATF-2 in the complex at the ATF/CRE site. Exp Cell Res 1995; 216: 422-430.

30. Page K, Li J, Wang Y, Kartha S, Pestell RG, Hershenson MB. Regulation of cyclin D(1) expression and DNA synthesis by phosphatidylinositol 3-kinase in airway smooth muscle cells. Am J Respir Cell Mol Biol 2000; 23: 436-443.

31. Bhoumik A, Ronai Z. ATF2-A transcription factor that elicits oncogenic or tumor suppressor activities. Cell Cycle 2008; 7: 2341-2345.

32. Lau E, Kluger H, Varsano T, Lee K, Scheffler I, Rimm DL et al. PKCepsilon promotes oncogenic functions of ATF2 in the nucleus while blocking its apoptotic function at mitochondria. Cell 2012; 148: 543-555.

33. Towers E, Gilley J, Randall R, Hughes R, Kristiansen M, Ham J. The proapoptotic dp5 gene is a direct target of the MLK-JNK-c-Jun pathway in sympathetic neurons. Nucleic Acids Res 2009; 37: 3044-3060.

c) (1) $(5)$

Cell Death and Disease is an open-access journal published by Nature Publishing Group. This work is licensed under a Creative Commons Attribution-NonCommercialShareAlike 3.0 Unported License. To view a copy of this license, visit http://creativecommons.org/licenses/by-nc-sa/3.0/ 